Int. J. Electrochem. Sci., 14 (2019) $10162-10175$

\title{
Biofilm formation on Titanium and Titanium Oxide and its Characterization and Electrochemical Properties
}

\author{
G. Gallegos Ortega ${ }^{1}$, V.E. Reyes Cruz ${ }^{1}$, G. Urbano Reyes ${ }^{l}$, D. Manzano Arredonda ${ }^{2}$, \\ M.A. Veloz Rodríguez ${ }^{1}$, A. Trujillo Estrada ${ }^{1}$, M. Pérez Labra ${ }^{1}$, J.A. Cobos Murcia, ${ }^{1, *}$. \\ ${ }^{1}$ Autonomous University of the State of Hidalgo, Academic Area of Earth and Materials Sciences, \\ Pachuca-Tulancingo Street Km 4.5 s/n, Mineral de la Reforma, Hidalgo, C.P. 4183, Mexico. \\ ${ }^{2}$ National Institute of Medical Sciences and Nutrition Salvador Zubirán, Microbiology Laboratory, \\ Vasco de Quiroga Street Number 15, Belisario Domínguez colony, Section XVI, Tlalpan delegation, \\ Mexico City, C.P. 14000, Mexico. \\ "E-mail: jose cobos@uaeh.edu.mx
}

doi: 10.20964/2019.11.05

Received: 14 February 2019 / Accepted: 30 July 2019 / Published: 7 October 2019

This work studied the surface characterisation and the electrochemical evaluation of titanium (Ti) and anodised titanium (A-Ti) electrodes modified with a bacterial biofilm of a novel consortium composed of Enterobacter cloacae complex, Enterococcus gallinarum, Escherichia coli, Klebsiella pneumoniae, and Enterococcus faecium - the biological support media consisted of peptone casein nutrient broth (PCNB), and acid whey (AW) - with the purpose of evaluating the electrochemical response of noncarbonaceous materials with low interferences. This is useful for bio-electrodes, mainly biocathodes intended to operate in bioelectrochemical systems of substrates at neutral $\mathrm{pH}$ and acid $\mathrm{pH}$. For this, scanning electron microscopy (SEM) and electrochemical techniques of chronopotentiometry and voltammetry were used, following the biofilm growth after the inoculation of the bacterial consortium on the Ti and A-Ti materials, at times of $24 \mathrm{~h}$ and $168 \mathrm{~h}$. The results showed that it was possible to obtain biofilms of bacteria with a high efficiency in a period of 24 hours, noting that the A-Ti material favours the biofilm growth in terms of quantity, chemical stability and a biocathodic response. The biofilms demonstrated specific behaviours depending on the inoculation time and the biological support medium, with evidence of bacterial bodies coated by extracellular polymeric substances (EPS) in the AW media. These results allow the possibility of using $\mathrm{Ti}$ and $\mathrm{A}-\mathrm{Ti}$ materials in bioelectrochemical systems whose purpose is to treat whey solutions with an acidic $\mathrm{pH}$.

Keywords: Bio-electrode, Titanium, Anodised, Media, pH, Biofilm. 
(C) 2019 The Authors. Published by ESG (www.electrochemsci.org). This article is an open access article distributed under the terms and conditions of the Creative Commons Attribution license (http://creativecommons.org/licenses/by/4.0/). 